\title{
Improving women's knowledge about prenatal screening in the era of non-invasive prenatal testing for Down syndrome - development and acceptability of a low literacy decision aid
}

Sian Karen Smith ${ }^{1 *}$ D, Antonia Cai ${ }^{1}$, Michelle Wong ${ }^{1}$, Mariana S. Sousa ${ }^{1,2,3}$, Michelle Peate ${ }^{4}$, Alec Welsh ${ }^{5,6}$,

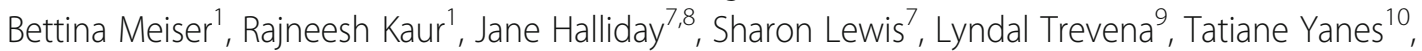

Kristine Barlow-Stewart ${ }^{11}$ and Margot Barclay ${ }^{12,13}$

\begin{abstract}
Background: Access to information about prenatal screening is important particularly in light of new techniques such as non-invasive prenatal testing (NIPT). This study aimed to develop and examine the acceptability of a low literacy decision aid (DA) about Down syndrome screening among pregnant women with varying education levels and GPs.

Methods: We developed a DA booklet providing information about first-trimester combined testing, maternal serum screening, and NIPT. GPs and women participated in a telephone interview to examine the acceptability of the DA and measure screening knowledge before and after reading the DA. The knowledge measure was designed to assess whether women had understood the gist of the information presented in the decision aid. It comprised conceptual questions (e.g. screening tells you the chance of having a baby with Down syndrome) and numeric questions (e.g. the accuracy of different screening tests).
\end{abstract}

Results: Twenty-nine women and 18 GPs participated. Regardless of education level, most women found the booklet 'very' clearly presented $(n=22,76 \%)$, and 'very' informative $(n=23,80 \%)$. Overall, women's conceptual and numeric knowledge improved after exposure to the DA, from 4\% having adequate knowledge to 69\%. Women's knowledge of NIPT also improved after receiving the decision aid, irrespective of education. Most GPs found it 'very' clearly presented $(n=13,72 \%)$, and that it would 'very much' facilitate decision-making $(n=16,89 \%)$.

Conclusions: The DA was found to be acceptable to women as well as GPs. A comprehensive evaluation of the efficacy of the decision aid compared to standard information is an important next step. Strategies are needed on how to implement the tool in practice.

Keywords: Decision aid, Informed decision-making, Prenatal screening, Prenatal testing, Trisomy 21, Down syndrome, Non-invasive prenatal testing (NIPT), Low literacy

\footnotetext{
* Correspondence: sian.smith@unsw.edu.au

${ }^{1}$ Psychosocial Research Group, Lowy Research Centre, C25, Prince of Wales

Clinical School, Faculty of Medicine, UNSW Sydney, Corner High and Botany

St, Kensington, Sydney New South Wales 2033, Australia

Full list of author information is available at the end of the article
}

(c) The Author(s). 2018 Open Access This article is distributed under the terms of the Creative Commons Attribution 4.0 International License (http://creativecommons.org/licenses/by/4.0/), which permits unrestricted use, distribution, and reproduction in any medium, provided you give appropriate credit to the original author(s) and the source, provide a link to the Creative Commons license, and indicate if changes were made. The Creative Commons Public Domain Dedication waiver (http://creativecommons.org/publicdomain/zero/1.0/) applies to the data made available in this article, unless otherwise stated. 


\section{Introduction}

Screening in early pregnancy for foetal abnormalities is an established part of routine care in Western countries [1]. Some countries, such as the UK and the Netherlands offer prenatal screening as part of their national screening programmes and costs are reimbursed [2,3]. Other countries have not implemented screening programmes, but have policies in place to ensure women are made aware that screening tests are available [4]. Irrespective of a women's age or family history, a nuchal translucency ultrasound, with or without a maternal serum test is generally available to women in early pregnancy to assess a woman's risk of carrying a foetus with chromosomal abnormalities. The most common chromosome condition is Down syndrome which can lead to varying degrees of physical, behavioural, and cognitive problems. If an increased risk is identified, invasive diagnostic tests such as amniocentesis and chorionic villus sampling are available. Women could then be faced with the decision of terminating the pregnancy or preparing for the birth of a child with special needs $[5,6]$.

Following the discovery of cell-free foetal DNA in the mother's blood, non-invasive prenatal testing (NIPT) is steadily becoming available to screen for Down syndrome in early pregnancy $[7,8]$. NIPT is more accurate than conventional screening with a higher detection rate (99\% versus $\sim 80-90 \%$, respectively) $[9,10]$, and eliminates the risk of miscarriage associated with invasive tests [11]. Accuracy, safety, and peace of mind are often cited as the perceived benefits of NIPT by women and health care professionals [12, 13]. NIPT has largely been driven by the commercial sector [14]. However, several European countries have evaluated the impact of integrating NIPT into existing prenatal screening programmes [15-17]. In Australia, the context for current study, women have to fund NIPT themselves as it is not available on Medicare or reimbursed through private insurance [18]. Existing Australian clinical guidelines state that all pregnant women should be offered NIPT as an option, and that health care professionals should be informed about NIPT and how it fits into current screening and diagnostic pathways [19]. As such, different approaches have been adopted in different practices, and information provision is likely to vary.

Access to decision support information in early pregnancy is essential for making informed decisions, particularly in light of the availability of NIPT and the perception that it is "just a blood test" $[20,21]$. The hallmarks of such decisions are possessing good knowledge of the consequences of participating in, or declining screening, being able to deliberate the options and outcomes, and making a choice consistent with their attitudes [22].
Decision aids (DAs) are tools designed to help people to make informed health decisions by explicitly stating the decision, providing information about the potential benefits and risks, and by clarifying values [23]. In prenatal care, DAs increase knowledge, lower decisional conflict and reduce anxiety [24]. An environmental scan of publicly available prenatal testing DAs - a process whereby internal and external data sources were searched, namely the DA Library Inventory, correspondence with research networks, and electronic databases - found that none of the 20 DAs identified fulfilled the International Patient Decision Aid minimum standards [25]. Only a few DAs included values clarification exercises, and most were developed prior to the availability of NIPT, with the exception of a web-based multimedia decision aid [26]. In addition, prenatal screening DAs rarely acknowledge the involvement of health care professionals in decision-making. Yet, health care professionals play an important role in supporting informed reproductive choices. [27]. In Australia, General Practitioners (GPs) or primary care physicians, are well positioned to provide decision support information about prenatal screening as they are typically the first health professional that women meet in the early stages of pregnancy when screening decisions are made.

A key challenge when designing health information is making sure that it is accessible and understood to people with different education and literacy skills [28]. Even women with higher levels of education may not be familiar with the various screening tests and struggle to understand information if it not communicated clearly [29]. In Australia, low health literacy is common, and up to $60 \%$ of the general population experience difficulties accessing and understanding information [30]. While there are prenatal screening decision aids [26, 31], few have been specifically developed using low literacy design principles to help expectant couples better understand information on equitable basis regardless of their education and literacy level [32].

To address the gaps highlighted above, this descriptive study aimed to: (1) develop a low literacy DA about prenatal screening for Down syndrome including NIPT, to complement counselling by a GP or other antenatal health care professional, (2) examine the acceptability and comprehensibility of the DA among GPs and among women with different education levels, and elicit suggestions for improvement, and (3) measure women's screening knowledge about the different screening tests available (including NIPT) before and after receiving the decision aid. 


\section{Method}

\section{Development of the low literacy DA}

The DA was developed by a multidisciplinary steering committee (all authors) of health professionals and researchers with expertise in epidemiology, genetics education, genetic counselling, psychology, DA development, and maternal foetal medicine. Existing Australian prenatal screening resources and the International Patient Decision Aid Standards (IPDAS) informed the content [33-35]. The DA was designed as a written booklet because our previous work found that women preferred paper-based information [36]. It is intended to complement rather than replace information or counselling by a GP or other health care professional.

Various low-literacy design strategies were applied, including; plain language; colour coding; glossary of medical terms; visual illustrations; simple medical diagrams; and providing contextual information before factual information [37-40]. The first draft of the DA was piloted with the target group, namely six pregnant women (mean age 31 years) with lower and higher education attending a hospital-based ultrasound clinic - 3 women with higher school certificate, and 3 had completed a university degree. The DA was then further refined based on their suggestions (e.g. using brighter colours and presenting culturally sensitive illustrations). Table 1 presents the DA content, including a 100-dot diagram (Fig. 1) and a worksheet (Fig. 2). The final version can be found - http://www.psychosocialresearchgroupunsw.org/decision-aids.html.

\section{Acceptability of the DA $G P$ recruitment and procedure}

GPs were invited to provide feedback on the DA and assist in recruiting eligible women. Invitation letters were sent to 320 GPs working in antenatal shared care listed on a hospital database in South Western Sydney, New South Wales (NSW), Australia. South Western Sydney is a metropolitan part of Sydney, with a higher proportion of lower socioeconomic groups compared to other areas of Sydney [41]. In Australia, antenatal shared care is an arrangement where pregnancy care is shared between the GP and the hospital or other birth setting. GPs who offer shared care must have extra training and qualifications [42]. NSW does not have a state-wide prenatal screening programme and often women have to pay for screening tests privately. NSW Health policy states that women should be made aware of screening and be supported in making an informed decision [43].

Interested GPs returned an expression of interest form and were visited by researchers (AC and SS), who explained the recruitment process, obtained written informed consent, and provided information packs (recruitment sheet, participant information sheet and

Table 1 Decision aid content

\begin{tabular}{|c|c|}
\hline Component/feature & Description \\
\hline \multirow[t]{2}{*}{ General description } & - Paper-based, 36-page, A5 booklet. \\
\hline & $\begin{array}{l}\text { - Written and quantitative information about prenatal screening (including NIPT) and } \\
\text { diagnostic testing for Down syndrome. }\end{array}$ \\
\hline Theoretical Framework & $\begin{array}{l}\text { - Systemic functional linguistics were used to structure the information (Clerehan, } \\
\text { Buchbinder et al. 2005). }\end{array}$ \\
\hline \multirow[t]{5}{*}{ Visual, format and design aspects } & - Plain language, headings, bullet points, and white space were used. \\
\hline & - Colour coding was consistently used to distinguish between screening and diagnostic tests. \\
\hline & $\begin{array}{l}\text { - A timeline was included to outline the timing of the different screening tests. Visual } \\
\text { illustrations were used throughout the booklet to support key concepts and break up the } \\
\text { text. }\end{array}$ \\
\hline & $\begin{array}{l}\text { - The image on the front cover was designed to set the scene for the booklet - a women } \\
\text { contemplating the options. }\end{array}$ \\
\hline & - Medical diagrams were presented of diagnostic testing. \\
\hline \multirow[t]{7}{*}{ Key factual content } & - The difference between screening and diagnostic tests. \\
\hline & - The chromosome conditions screened for. \\
\hline & - The different types of screening tests (first-trimester, second-trimester and NIPT). \\
\hline & - Accuracy of screening testing in detecting Down syndrome. \\
\hline & - Diagnostic testing. \\
\hline & - Options available after a diagnosis of Down syndrome. \\
\hline & - Personal worksheet to help women/ couples decide about prenatal screening (Fig. 2). \\
\hline Presentation of quantitative information & $\begin{array}{l}\text { - Systematic 100-dot diagrams (see Fig. 1) used to convey sensitivity (rate at which women } \\
\text { carrying babies with Down syndrome are detected) of the Combined First Trimester } \\
\text { screening, Second Trimester Maternal Serum Screening and Non-Invasive Prenatal testing. }\end{array}$ \\
\hline
\end{tabular}




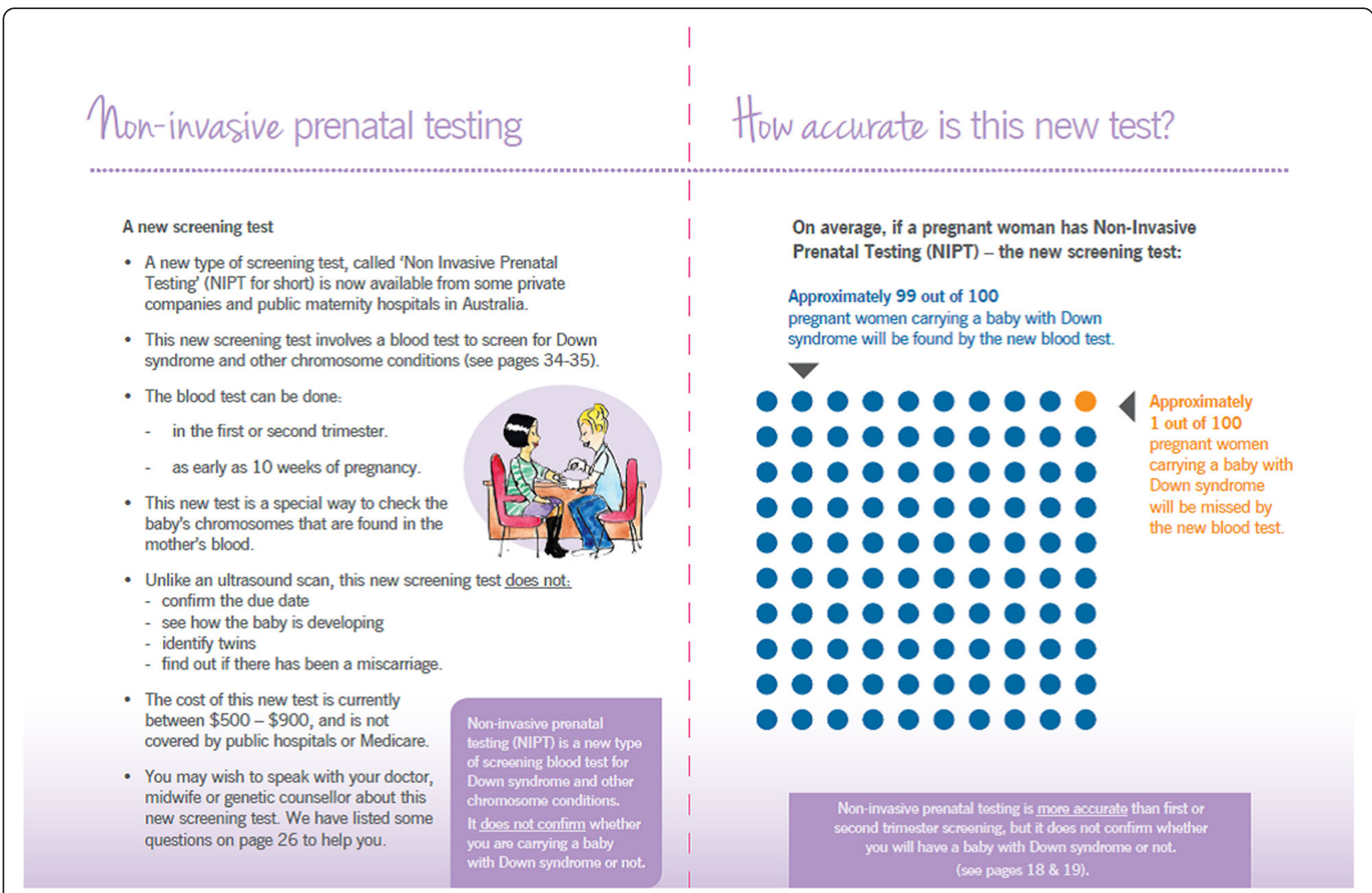

Fig. 1 100-dot diagram illustrating the accuracy of NIPT

DA). GPs were asked to invite all eligible women, until the target sample size of 30 was reached. In our previous decision aid work, a sample size of 30 has been found to be suitable for obtaining feedback on the acceptability and comprehensibility of DAs $[44,45]$. We also telephoned GPs individually about once a month to thank them for their commitment to the study, and to identify barriers to recruitment and discuss ways to boost recruitment.

GPs took part in a 30-min telephone interview using closed/structured and open-ended questions to obtain feedback on the DA. The current study reports the responses to the structured questions; the qualitative data will be reported in a separate paper. For participation, GPs received continuing professional development points from the Royal Australian College of General Practitioners.

\section{Recruitment of pregnant women and procedure}

Eligible women were invited by their GP and given an information sheet. Women were eligible if they were aged 16 years or older, were able to speak English and equal to or less than 13 weeks and 2 days of gestation. This cut-off time was chosen because in Australia combined first trimester screening is carried out between 9 weeks and 13 weeks (plus 6 days). This cut-off point enabled us to recruit women slightly later on in gestation to widen the recruitment window [46]. Women who expressed an interest were contacted by researchers (AC \& TY) to determine eligibility, obtain verbal consent, and measure knowledge prior to receiving the DA. Eligible and consenting participants were mailed a copy of the DA and telephoned approximately 2 weeks later to collect socio-demographic information, elicit DA feedback, and measure knowledge. To increase recruitment, we offered women reimbursement for their time (a gift voucher), and sent a monthly newsletter to GPs to update and remind them to recruit potential participants.

Participants were recruited between 2014 and 2015. Ethics approval was obtained from the South Eastern and South Western Sydney Local Health District Human Research Ethics Committees (ref number: 12/219).

\section{Measures}

\section{GP measures}

Socio-demographic data were collected from GPs. Closed questions (using Likert rating scales) adapted from our previous research were used to examine perceptions of its length, balance, clarity, and usefulness 


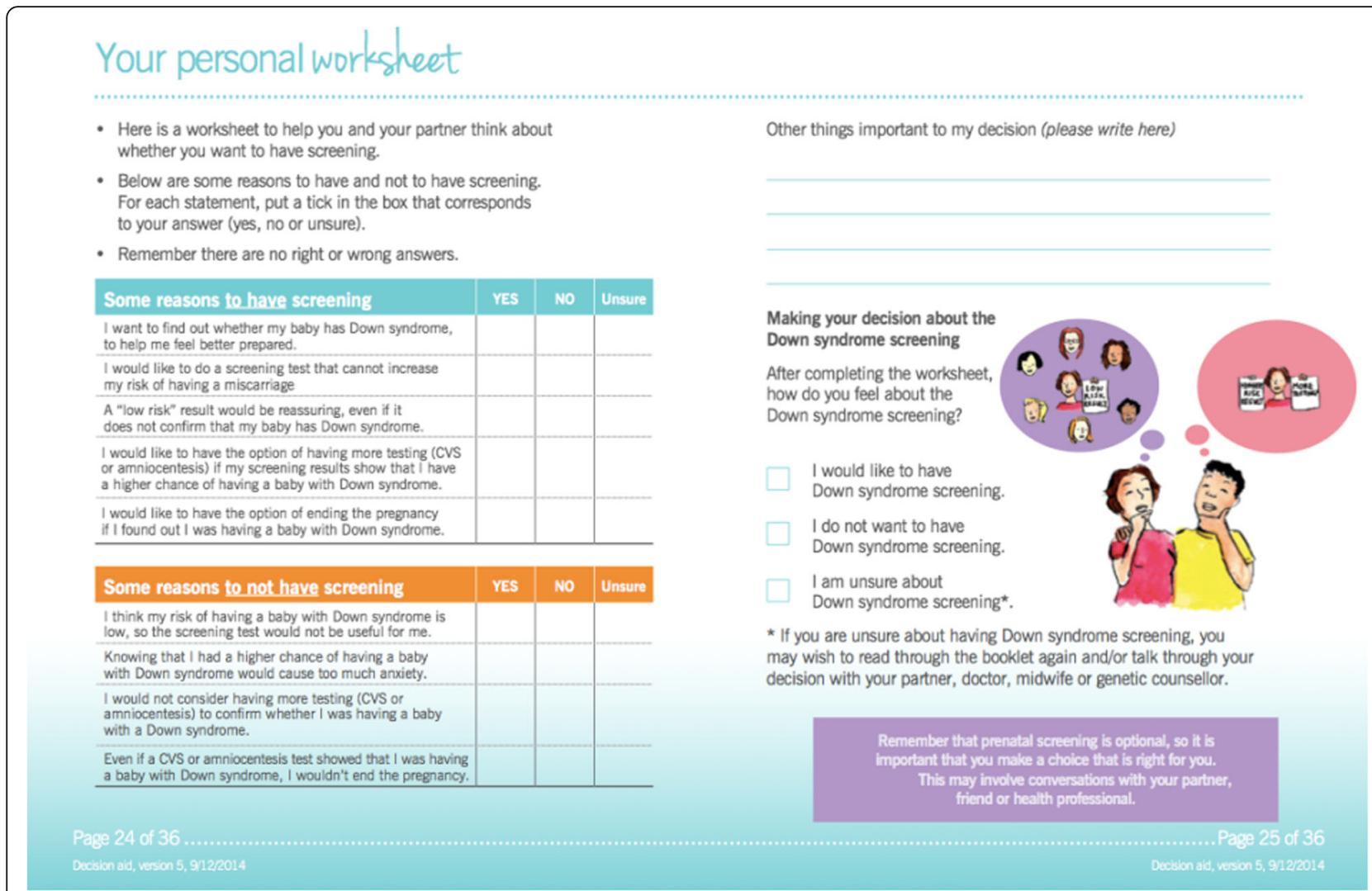

Fig. 2 Personal worksheet included in the DA

[47]. Some open-ended questions were asked to elicit feedback on how to improve the DA.

\section{Women measures: Socio-demographic and obstetric variables}

Data on age, marital status, educational level, country of birth, years lived in Australia, first language, employment status, occupation, previous pregnancy outcomes and screening experience were collected.

\section{$D A$ acceptability and comprehensibility}

Closed questions using Likert rating scales examined the acceptability of the DA in terms of its length, balance, clarity, and amount of information. Comments on the illustrations, colour coding, diagrams, and worksheet were elicited using open-ended questions, and participants were asked to offer suggestions on how to improve the DA.

\section{Knowledge}

Knowledge is a key component of informed decision-making. Prenatal screening knowledge was measured to identify the extent to which women's knowledge changed before and after exposure to the DA, and examine whether the resource would help inform women's decision-making during pregnancy. The knowledge questions and marking scheme were informed by Fuzzy Trace Theory, a dual-process theory which proposes two ways in which people process and store information in their memory: (i) processing and remembering the bottom-line meaning ('gist'), and (ii) processing and recalling information precise details ('verbatim') [48]. When making decisions, studies have shown that gist information processing tends to be superior to verbatim processing in improving the quality of the decision, possibly because it relies less on remembering the exact details [49] As such, our knowledge measure was designed to assess whether women understood the 'gist' of the information, including their (i) conceptual knowledge of screening for Down syndrome (e.g. screening tells you the chance of having a baby with Down syndrome) and, (ii) numeric knowledge (e.g. the accuracy of different screening tests). Nineteen items with true/false response options, adapted from previous questions developed by [50] and our previous work [51]. Existing knowledge measures did not include questions about NIPT so we developed our own items. A scoring scheme was developed providing a maximum score of 22 (16 for conceptual knowledge and 6 for numeric 
knowledge) (Additional file 1 knowledge scoring scheme and questions). It was decided a priori that a score of $75 \%$ or above (score $\geq 17$ out of 22 ) would be considered 'adequate knowledge'. Although the 75\% knowledge threshold might be considered high, it enabled us to identify whether the conceptual and numeric knowledge scales were responsive to exposure to the DA. Thus, to achieve 'adequate knowledge', participants needed to answer a combination of conceptual and numeric questions correctly.

\section{Data analysis}

Data were analysed using SPSS 24.0 (Statistical Program for the Social Sciences. Basic descriptive statistics, including means, medians, percentages, ranges and standard deviations were calculated to describe the samples in terms of socio-demographic characteristics.

\section{Results}

\section{GP sample characteristics}

Twenty-two GPs returned an expression of interest form and 18 GPs consented. The mean age of the GPs was 45 years (range $28-66$ years), $72 \%$ were female, $50 \%$ were born in Australia, and $40 \%$ had more than 20 years' experience (Table 2).

\section{Women sample characteristics}

All of the GPs managed to invite at least one woman to participate. A total of 59 pregnant women were initially invited to take part. Of these, 22 did not meet the eligibility criteria and 8 were not interested. A total of 29 eligible women agreed to participate.

The mean age of the women was 32 years (range 25-40 years) (Table 3). Seventeen of the 29 women (59\%) had a university education, 7 (24\%) had a trade or technical qualification, and $5(17 \%)$ had completed high (secondary) school education (aged between 15 and 16 years) or had achieved a Higher School Certificate. The Higher School Certificate (HSC) is the qualification awarded to senior high school students in Years 11 and 12 (aged between 16 to 18 years) who successfully complete high school. Participants were divided into two groups - (i) Higher education $(n=17,59 \%)$ - undergraduate or postgraduate degree and, (ii) Lower education $(n=12,41 \%)$ - completed secondary/ high school education or had successfully completed a Higher School Certificate, or trade/technical/ vocational qualifications.

\section{Acceptability of the DA}

\section{GPs}

Most GPs felt that the information was 'very' clear $(n=13,72 \%)$, 'very' easy to read $(n=13,72 \%)$, 'very' useful $(n=16,89 \%)$, and 'very' appealing $(n=14$,
Table 2 GP Characteristics $(n=18)^{a}$

\begin{tabular}{|c|c|}
\hline Characteristics & $N(\%)$ \\
\hline \multicolumn{2}{|l|}{ Age (years) } \\
\hline Mean & 45 \\
\hline Range & $28-66$ \\
\hline \multicolumn{2}{|l|}{ Gender } \\
\hline Male & $5(28)$ \\
\hline Female & $13(72)$ \\
\hline \multicolumn{2}{|l|}{ Country of birth } \\
\hline Australia & $9(50)$ \\
\hline South-East Asia & $5(33)$ \\
\hline Africa & $3(16)$ \\
\hline UK & $1(6)$ \\
\hline \multicolumn{2}{|l|}{ Primary language } \\
\hline English & $11(61)$ \\
\hline Other & $7(39)$ \\
\hline \multicolumn{2}{|c|}{ Years of experience as a GP } \\
\hline Less than a year & $3(20)$ \\
\hline $1-5$ years & $1(7)$ \\
\hline $6-10$ years & $2(13)$ \\
\hline $11-20$ years & $3(20)$ \\
\hline $21-30$ years & $5(33)$ \\
\hline $31+$ years & $1(7)$ \\
\hline \multicolumn{2}{|l|}{ Employment status } \\
\hline Full-time & $13(72)$ \\
\hline Part-time & $5(28)$ \\
\hline \multicolumn{2}{|c|}{ Current role in general practice } \\
\hline Registrar/in training & $4(22)$ \\
\hline Contractor/sessional & $7(39)$ \\
\hline Retainer/salaried & $3(17)$ \\
\hline Partner/principal & $4(22)$ \\
\hline
\end{tabular}

${ }^{a}$ Some percentages do not add up to $100 \%$ due to rounding

78\%) (Table 4). All GPs described the DA as 'very' informative $(n=18,100 \%)$. The majority of GPs felt that the DA presented a balanced view of prenatal screening ( $n=16,89 \%)$, and would 'very much' assist women/couples in helping them to better understand about screening $(n=15,83 \%)$ and facilitate their decision-making ( $n=16,89 \%)$.

Most felt the DA would make it 'somewhat' or 'much' easier to communicate to women about screening ( $n=16$, $88 \%)$. Just over half of GPs $(n=10,56 \%)$ thought it would be 'very' feasible to implement the DA into practice, whereas the remaining GPs felt it would be 'somewhat' more challenging $(n=8,44 \%)$. Half of the GPs described the information in the DA as just the right amount $(n=9$, $50 \%$ ), and the other half thought it would be 'too much' for women $(n=9,50 \%)$. 
Table 3 Characteristics of the women $(n=29)^{\text {a }}$

\begin{tabular}{l} 
Characteristics \\
\hline Socio-demographic characteristice (years) \\
Mean \\
Range \\
Marital Status \\
Married \\
Living with partner \\
Not living with partner \\
Educational level \\
Year 10 or below \\
Year 12 Higher School Cert \\
Trade or technical certifict \\
Bachelors/Undergraduate \\
Postgraduate degree \\
Country of birth \\
Australia \\
Other \\
Language/s spoken at home \\
English only \\
Bilingual \\
Current employment status \\
Full-time employed \\
Part-time employed \\
Self-employed \\
Homemaker \\
Student
\end{tabular}

Has private health insurance

Yes

No

Obstetric variables

First pregnancy

Yes

No

Previous pregnancy outcomes

Previously experienced a miscarriage

Previously experienced a termination of pregnancy

Previous screening tests

Yes

No

Unsure

Previous diagnostic tests

$$
\text { No }
$$

Unsure

${ }^{a}$ Some percentages do not add up to $100 \%$ due to rounding

${ }^{b}$ In Australia, Year 10 is the 10th full year of compulsory secondary (or high school) education with students aged between 15 and 16 years. By the end of Year 10, all qualifying students complete secondary (high) school

'Senior secondary (high) school education runs from Year 11 and Year 12 with students aged between 16 to 18 years. The Higher School Certificate (HSC) is the qualification awarded to senior secondary school students who successfully complete senior high school
Table 4 GP responses regarding the acceptability of the DA $(n=18)$

\begin{tabular}{ll}
\hline Questions and responses options & $N(\%)$ \\
\hline How clear was the information? & $13(72)$ \\
Very & $5(28)$ \\
Somewhat &
\end{tabular}

How informative was the DA?

$$
\text { very }
$$

How easy to read was the DA

$\begin{array}{ll}\text { Very } & 13(72) \\ \text { Somewhat } & 3(17) \\ \text { Not at all } & 2(11) \\ \text { How useful was the DA? } & 16(89) \\ \text { Very } & 2(11) \\ \text { Somewhat } & \\ \text { How appealing was the DA? } & 14(78) \\ \text { Very } & 4(22)\end{array}$

How would you describe the amount of information?

$$
\begin{array}{ll}
\text { Just right } & 9(50) \\
\text { Too much } & 9(50)
\end{array}
$$

How balanced did you find the information?

$\begin{array}{ll}\text { Completely balanced } & 16(89) \\ \text { Encouraging prenatal screening } & 2(11)\end{array}$

Will the DA make it easier for you to communicate with patients?

$\begin{array}{ll}\text { Very much } & 8(44) \\ \text { Somewhat } & 8(44) \\ \text { Not at all } & 2(11)\end{array}$

Do you think the DA will assist women/couples in helping them to understand about prenatal screening?

$\begin{array}{ll}\text { Very much } & 15(83) \\ \text { Somewhat } & 3(17)\end{array}$

Do you think the DA will assist women/couples in making decisions?

$$
\begin{array}{ll}
\text { Very much } & 16(89) \\
\text { Somewhat } & 2(11)
\end{array}
$$

How feasible would it be to implement the DA into routine practice?

$\begin{array}{ll}\text { Very } & 10(56) \\ \text { Somewhat } & 5(28) \\ \text { Not very } & 3(16)\end{array}$

\section{Women}

Overall, women reacted positively towards the DA (Table 5). The majority of participants reported reading all the information $(n=25,86 \%)$, and that it took them less than $30 \mathrm{~min}$ to $\mathrm{read}(n=23,79 \%)$. Around half of the women reported that 'all' or 'most' of the information was new to them $(n=15,51 \%)$. Most women felt the DA presented a balanced view of screening $(n=21,72 \%)$, 
Table 5 Women's responses regarding the acceptability of the decision aid by higher and lower education groups ${ }^{\mathrm{a}}$

\begin{tabular}{|c|c|c|c|}
\hline \multirow[t]{2}{*}{ Questions and response options } & Higher education $(n=17)$ & Lower education $(n=12)$ & Total women $(n=29)$ \\
\hline & $N(\%)$ & $N(\%)$ & $N(\%)$ \\
\hline \multicolumn{4}{|l|}{ How much of the DA did you read? } \\
\hline I read all of it & $14(82)$ & $11(92)$ & $25(86)$ \\
\hline I read part of it & $0(0)$ & $1(8)$ & $1(3)$ \\
\hline My GP went through it with me & $1(6)$ & $1(8)$ & $2(7)$ \\
\hline \multicolumn{4}{|l|}{ How long did it take you to read it? } \\
\hline Less than thirty minutes & $14(82)$ & $9(75)$ & $23(79)$ \\
\hline More than thirty minutes & $3(18)$ & $3(25)$ & $6(21)$ \\
\hline \multicolumn{4}{|c|}{ What about the amount of information? } \\
\hline Not enough & $3(18)$ & $2(18)$ & $5(18)$ \\
\hline Just right & $12(71)$ & $8(73)$ & $20(71)$ \\
\hline Too much & $2(12)$ & $1(9)$ & $3(11)$ \\
\hline \multicolumn{4}{|l|}{ How balanced was the information? } \\
\hline Encouraging prenatal screening & $6(35)$ & $2(17)$ & $8(28)$ \\
\hline Completely balanced & $11(65)$ & $10(83)$ & $21(72)$ \\
\hline \multicolumn{4}{|l|}{ Order of topics presented } \\
\hline I liked the order & $13(89)$ & $11(92)$ & $24(89)$ \\
\hline I'm not sure & $2(13)$ & $1(8)$ & $3(11)$ \\
\hline \multicolumn{4}{|c|}{ How much of the information was new? } \\
\hline All or most & $10(59)$ & $5(41)$ & $15(51)$ \\
\hline Some & $7(41)$ & $6(50)$ & $13(45)$ \\
\hline None & $0(100)$ & $1(8)$ & $1(3)$ \\
\hline \multicolumn{4}{|l|}{ Did you show the booklet to anyone? } \\
\hline Yes & $11(65)$ & $7(58)$ & $18(62)$ \\
\hline No & $6(35)$ & $5(42)$ & $11(38)$ \\
\hline \multicolumn{4}{|l|}{ Who did you show the booklet to? } \\
\hline Husband/partner & $9(53)$ & $6(50)$ & $15(52)$ \\
\hline Friend who is pregnant & $0(0)$ & $1(8)$ & $1(3)$ \\
\hline GP + husband/partner & $2(12)$ & $0(0)$ & $1(7)$ \\
\hline \multicolumn{4}{|l|}{ Would you recommend the DA? } \\
\hline Yes I would & $14(82)$ & $9(75)$ & $23(79)$ \\
\hline I'm not sure & $2(12)$ & $2(17)$ & $4(14)$ \\
\hline No & $1(6)$ & $1(8)$ & $2(7)$ \\
\hline \multicolumn{4}{|c|}{ How worried you felt after reading the DA? } \\
\hline Not at all & $8(47)$ & $7(58)$ & $15(52)$ \\
\hline A little bit & $5(29)$ & $5(42)$ & $10(35)$ \\
\hline Somewhat & $4(24)$ & $0(0)$ & $4(14)$ \\
\hline \multicolumn{4}{|l|}{ Did you use the worksheet? } \\
\hline Yes & $5(29)$ & $5(42)$ & $10(34)$ \\
\hline No & $12(71)$ & $7(58)$ & $19(66)$ \\
\hline \multicolumn{4}{|c|}{ Please indicate if you thought the booklet was... } \\
\hline Clearly presented & $12(71)$ & $10(83)$ & $22(76)$ \\
\hline Informative & $13(77)$ & $10(83)$ & $23(80)$ \\
\hline Easy to read & $13(77)$ & $11(92)$ & $24(83)$ \\
\hline
\end{tabular}


Table 5 Women's responses regarding the acceptability of the decision aid by higher and lower education groups ${ }^{a}$ (Continued)

\begin{tabular}{llll}
\hline Questions and response options & Higher education $(n=17)$ & Lower education $(n=12)$ & Total women (n=29) \\
& $N(\%)$ & N (\%) & $24(83)$ \\
\hline Useful & $14(82)$ & $10(83)$ & $9(75)$ \\
Appealing to look at & $10(59)$ & & $19(66)$ \\
How helpful was the DA in terms of... & & $10(83)$ & $25(86)$ \\
Increasing understanding of options & $15(88)$ & $9(75)$ & $18(62)$ \\
Clarifying the benefits of each option & $9(53)$ & $8(67)$ & $20(69)$ \\
Clarifying the risks of each option & $12(71)$ & $8(67)$ & $16(55)$ \\
Clarifying your decision-making & $8(47)$ & $6(50)$ & $14(48)$ \\
Helping you reach a decision & $8(47)$ & & \\
\hline
\end{tabular}

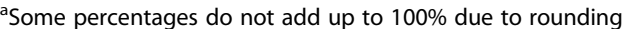

although a slightly higher proportion of women with higher education thought it was encouraging screening $(n=6,35 \%)$ compared to those with lower education $(n=2,17 \%)$. Most women thought the amount of information was 'just right' $(n=20,71 \%)$, with only a few finding it to be 'too much' information ( $n=3,11 \%)$.

Most women found the booklet 'very' clearly presented ( $n=22,76 \%)$, 'very' informative $(\mathrm{n}=23,80 \%)$, 'very' easy to read $(n=24,83 \%)$, and 'very' useful $(n=24,83 \%)$ (Table 5). Slightly fewer women described the DA as 'very visually appealing to look at' ( $n=19,66 \%)$. The majority of women felt the booklet was 'very' helpful in increasing their understanding of the options $(n=25,86 \%)$. Around half of the women reported it being 'very' helpful in clarifying their decision-making $(n=16,55 \%)$ and reaching a decision $(n=$ $14,48 \%)$. Just over a third of women reported completing the personal worksheet $(n=10,34 \%)$.

\section{Women's responses to the open-ended questions}

All of the women found the font size appropriate. The colours were described as 'bright', and 'consistent'. The illustrations and diagrams were generally well received; being described as 'appropriate', and 'a good mix of cultures'. However, a few women did not like the illustrations and found them 'condescending' and too 'upbeat' considering the serious nature of the topic.

The summary sheet, timeline, worksheet and glossary of medical words were described as 'useful', and helping to 'put it into perspective'. The 100 dot-diagrams (Fig. 1) received mixed responses - some described them as 'a clever visual representation', whereas others thought they were 'difficult to grasp' in terms of what they were representing (i.e. pregnant women carrying a baby with Down syndrome).

\section{Women's screening knowledge - Conceptual and numeric}

Overall, there was a difference in women's knowledge before and after exposure to the DA, with mean scores increasing from 12.7 (out of 22) to 18.3 (Table 6).
Conceptual knowledge scores improved from 12.0 to 14.4 (out of 16), and numeric knowledge scores increased from 0.7 to 3.9 (out of 6). Women's knowledge about NIPT also improved from 2.1 to 4.1 (out of 5) after receiving the decision aid. Both education groups showed improvements, and a slightly higher proportion of women with higher education had increased knowledge compared to women with lower education (77\% versus $58 \%$, respectively).

\section{Key revisions to the DA based on participant feedback}

Both women and GPs had useful suggestions on how to improve the booklet. The following revisions were made in accordance with their feedback. We included a summary page comparing the accuracy and potential risks (i.e. miscarriage) of the different types of screening and diagnostic tests so the reader had all the information in one to which they could refer to in their decision-making. Both women and GPs wanted more practical information on where NIPT could be done and who to ask about it; we included a list of questions about NIPT that women could ask their GP, or other antenatal health professional. Some women were interested to know where they could find more information on the practicalities or impact of raising a child with Down syndrome. As such, in our revisions, we provided details of several resources produced by Down syndrome Australia. Some GPs felt the booklet should explain that screening requires medical referral, and clarify that screening identifies other chromosomal conditions. Throughout the booklet, we made some wording changes in accordance with Down syndrome Australia protocol on how to communicate with the public about Down syndrome. For example, we replaced the term 'risk' with 'chance', and 'problem' or 'disease' with 'condition'. Based on GP feedback, we described diagnostic tests as 'definite' tests and replaced 'detecting Down syndrome' with 'identifying Down syndrome'. We also reworded the 100-dot diagrams to clarify that the 
Table 6 Women's conceptual and numeric screening knowledge before and after receiving the decision aid by education group

\begin{tabular}{|c|c|c|c|}
\hline & $\begin{array}{l}\text { Higher education } \\
(n=17)\end{array}$ & $\begin{array}{l}\text { Lower education } \\
(n=12)\end{array}$ & $\begin{array}{l}\text { Total women } \\
(n=29)\end{array}$ \\
\hline \multicolumn{4}{|l|}{ Pre Knowledge Scores, Mean (SD) ${ }^{a}$} \\
\hline Conceptual (maximum score 16) & $12.1(1.7)$ & $11.9(2.2)$ & $12(1.9)$ \\
\hline Numeric (maximum score 6) & $0.9(1.4)$ & $0.3(0.7)$ & $0.7(1.2)$ \\
\hline NIPT knowledge (maximum score 5) & $2.1(1.2)$ & $2.2(0.6)$ & $2.1(1.0)$ \\
\hline Total knowledge score (max score n) & $13.1(2.3)$ & 12. $2(1.8)$ & $12.7(2.1)$ \\
\hline Adequate knowledge $^{\mathrm{b}}$ (total score $\geq 17$ out of 22 ), $n$ (\%) & $1(6)$ & $0(0)$ & $1(4)$ \\
\hline \multicolumn{4}{|l|}{ Post Knowledge Scores, Mean (SD) } \\
\hline Conceptual (maximum score 16) & $14.7(1.4)$ & $14.1(1.5)$ & $14.4(1.4)$ \\
\hline Numeric (maximum score 6) & $4.2(2.4)$ & $3.4(2.4)$ & $3.9(2.4)$ \\
\hline NIPT knowledge (maximum score 5) & $4.3(1.0)$ & $3.8(1.1)$ & $4.1(1.09)$ \\
\hline Total knowledge score (max score 22) & $18.9(3.2)$ & $17.5(3.4)$ & $18.3(3.3)$ \\
\hline Adequate knowledge (total score $\geq 17$ out of 22 ), $n$ (\%) & $13(77)$ & $7(58)$ & $20(69)$ \\
\hline
\end{tabular}

a Data missing for 1 participant

${ }^{b}$ Participants were classified as having 'adequate' or 'inadequate' knowledge using the midpoint of the scale. It was decided a priori that a pass mark of $75 \%$ or above (score $\geq 17$ out of 22 ) would be considered 'adequate knowledge'

diagrams represented 100 pregnant women carrying a baby with Down syndrome.

\section{Discussion}

This article describes the development and acceptability of a low literacy DA about Down syndrome screening. The DA was well received by women with different education levels and GPs. Women's knowledge of the different types of screening tests, including NIPT, increased after exposure to the DA. Most women felt the information was very clearly presented, easy to read, informative, and rated the amount of information and length favourably. The DA was considered to be relevant, with most reporting they would recommend it to others. Similarly, most GPs reported the DA as clear, and that it would assist women in decision-making.

Although conceptual and numeric knowledge increased for both higher and lower education groups, a slightly higher proportion of women with higher education were found to have adequate knowledge compared to those with lower education. Although this is a small sample, it nonetheless echoes previous work showing that women from lower education groups experience greater difficulties making an informed decision [32]. Similarly, women with higher education have shown to benefit more from decision aids than those with lower education, possibly because they are more familiar with the engaging in decision-making and critically appraising health information [33, 47, 52].

Both women and GPs reviewed the DA positively, and there were few discrepancies in their views towards it. However, they did differ with regard to the amount of information, with half of the GPs thinking there was too much information, yet most women thinking it was just about right. Women expressed the need for more experiential information about living with a child who has Down syndrome. The final version includes website links with information about this. It is not uncommon for health professionals to underestimate how much information patients want to receive, possibly through fear of overloading patients, or underestimating their understanding [53].

Not all GPs agreed that the DA would be easy to implement and some felt it would not necessarily facilitate communication. The challenges of implementing DAs in clinical practice are widely reported [54-56]. Although DAs have proven to be effective, they are not commonly used in practice because of communication, cultural, ideological, organisational, and practical barriers [57]. Lepine et al. (2016) identified a number of factors influencing whether health professionals would use a prenatal screening DA, ranging from whether the tool was positively appraised, considered relevant, or being readily accessible to having enough time and colleagues endorsing the tool [58].

Our results showed that around two-thirds of women reported not using the values clarification worksheet. Perhaps the information on its own without a values clarification exercise might be enough to improve knowledge and enhance decision-making [27, 59, 60], or women found it difficult to complete. There is debate about whether DAs interfere with intuitive forms of information processing, and exercises that encourage deliberative (slow and analytic) decision-making may not always lead to better decisions. Clearly, more research is needed as to explore the factors that influence people using values clarification exercises, who might benefit more from such methods, and whether information alone might be enough to clarify values. 
We note that GPs were the only health professionals involved in the study. Including other health professionals (e.g. midwives, obstetricians, and genetic counsellors) would have been useful to explore the diversity of perspectives. One study observed that health professionals varied in their attitudes towards using prenatal screening DAs; midwives seemed more positive about using DAs compared to GPs and obstetricians [58].

At the time of the study, NIPT was on the cusp of being implemented into the Australian healthcare system, predominately in the private health care system with test results being sent to offshore laboratories on a user pays basis with no reimbursement. At present, NIPT is more widely available in both the private and public healthcare system, and although it is less expensive than it used to be, it is still offered with no reimbursement. It is possible that discussions with health care professionals about NIPT may have influenced women's knowledge and understanding about NIPT, and women may have paid less attention to the decision aid because NIPT was too expensive for women to consider a viable option. However, we note that some GPs in our study were not fully aware of the availability of NIPT and found the decision aid to be informative in improving their own knowledge. Further, our results showed that women's knowledge of NIPT increased after exposure to the decision aid and they were able to correctly answer questions about accuracy of the NIPT that would have required reading the decision aid.

This study has a few limitations. Firstly, despite efforts to recruit partners to the study we were not successful. However, most women in the current study reported showing the DA to their partners, indicating that they valued their involvement. Similarly, previous research has shown screening decisions are often made by couples together [27, 36, 61, 62]. Others have also highlighted the challenges of recruiting men to participate in health research. Strategies have been proposed to help overcome men's resistance to participation, these include; emphasising the personal benefits and altruistic elements of the research, simplifying technical information, and using humour [63]. Future research should consider these recruitment strategies to ensure partners' perspectives are taken into account.

Secondly, although we made efforts to recruit women with varying education levels to ensure the tool was acceptable to different education groups, we encountered difficulties recruiting women from lower education groups. The length of recruitment was extended due to difficulties recruiting this group. This is perhaps not surprising given that lower socioeconomic groups are generally under-represented in health and medical research [64]. In addition, we did not measure participants' health literacy skills. While educational attainment is associated with literacy and health literacy, they are not synonymous. Further testing with higher and lower health literacy groups would be an important next step to identify whether the decision aid is suitable and understandable to different health literacy groups.

Thirdly, given the aims of the study were to provide descriptive data on the acceptability of the DA, the results should therefore be considered as preliminary. The small sample size in each education group meant that we were underpowered to perform statistical analyses to detect any statistical differences between the two groups. At this stage, it is not possible to make conclusive statements about the actual effect of the decision aid without a randomised controlled trial with a larger sample, to evaluate the efficacy of the DA compared to standard information. This will provide valuable evidence on the effect of the decision aid on informed decision-making (knowledge, attitudes, uptake, values consistency and deliberation), and enable us to generalise the findings to populations with different education levels.

Finally, in line with previous work [65], there was a very low response rate from GPs creating problems of non-response bias. GPs who responded may have had a stronger interest in prenatal screening and reactions to the DA may have been different among GPs who did not respond. Furthermore, although we asked GPs to invite all eligible pregnant women to participate, GPs may have selected women whom they thought had the necessary health literacy skills to read and understand the DA. We had considerable difficulties recruiting women with lower education levels throughout the study which subsequently delayed recruitment.

\section{Conclusion}

The DA was found to be acceptable, comprehensible, and useful to women from different educational backgrounds and GPs. Women's knowledge about screening, including NIPT, increased after exposure to the DA. The next steps will be to further test the DA among women with different health literacy skills, and then evaluate the efficacy of the DA on informed decision-making (knowledge, attitudes, values-consistency, deliberation) compared to standard information in a larger sample. It would also be important to identify strategies for how the tool could be more broadly used and implemented by GPs and other health professionals.

\section{Practice implications}

This is one of the few prenatal screening DAs to provide information about NIPT. It has the potential to provide prospective parents with clear and easy-to-read information, and complement existing information presented by health care professionals. A formal evaluation of the 
efficacy of the tool (compared to standard information) is necessary before it is made available.

Although all participants spoke English, around one-third of participants were bilingual. If translated into different languages, the DA could provide culturally and linguistically diverse (CALD) populations with a tool that is accessible in their own language and help to address the potential communication challenges. Future work could also focus on translating the DA into different languages to address the needs of those from CALD backgrounds.

Future work is also needed to identify and overcome the barriers to implementing DAs, with studies focused on identifying the contextual and facilitative mechanisms that could influence the implementation of the DA [66]. The potential use of social marketing, (the use of commercial marketing strategies to enhance public health and well-being [67], has also been suggested [57]. Future work could be directed towards identifying social marketing strategies (e.g. social media) to support the long-term implementation of DAs. We also note that this DA was developed in the context of the Australian healthcare system and the risk information presented is based on Australian data. The DA would need modification if tested in other countries.

\section{Additional file}

Additional file 1: Knowledge scoring scheme - questions and scoring scheme for the knowledge measure assessing conceptual and numeric knowledge of prenatal screening. (DOCX 20 kb)

\section{Abbreviations}

DA: Decision aid; NIPT: Non-invasive prenatal testing

\begin{abstract}
Acknowledgements
We thank the women who took the time to participate in the study, and the GPs who helped us to recruit women and provide feedback. Special thanks to Dr. Cecile Muller, Ms. Kate Talbot, Dr. Jane Lloyd, Dr. Kate Dunlop, Dr. Mona Saleh, Ms. Marilena Pelosi, and Assistant Professor Marie-Anne Durand for their useful comments on the DA. We acknowledge Fiona Katauskas for her illustrations and Relax Design for their assistance with the graphical design of the decision aids.
\end{abstract}

\section{Funding}

At the time of this study, Dr. Sian Smith was supported by an Early Career Research Fellowship from the Australian National Health and Medical Research Council (ID 1034912). Professor Bettina Meiser was supported through an NHMRC Senior Fellowship, Level B (ID 1078523). Dr. Michelle Peate is supported by an Early Career Fellowship from the National Breast Cancer Foundation (ECF-015). Prof Jane Halliday is supported by NHMRC Senior Fellowship, Level B (ID1021252). Ms. Yanes is supported by NHMRC Postgraduate Research Scholarship and National Breast Cancer Foundations (ID 1133049). The funders had no role in the design or conduct of the study, in the collection, analysis and interpretation of data, or in the preparation or approval of the manuscript.

\section{Availability of data and materials}

The datasets used and analysed during the current study are available from the corresponding author on reasonable request.

\section{Authors' contributions}

SS conceived the study. All authors (SS, AC, MW, MS, MP, AW, BM, RK, JH, SL, $\mathrm{LT}, \mathrm{KBS}, \mathrm{MB}$ ) contributed to the design and development of the prenatal screening decision aid. SS, TY, MW and AC coordinated data collection.

SS analysed the data and all of the authors contributed to interpreting it. SS wrote the first draft of the manuscript. All authors participated in writing and revising the draft manuscript critically for important intellectual content. All authors approved the final version of the manuscript.

\section{Ethics approval and consent to participate}

Ethics approval for the study was obtained from the South Eastern and South Western Sydney Local Health District Human Research Ethics Committees (ref number: HREC 12/219). Written informed consent was obtained from all GPs before they took part in the study. Verbal informed consent was obtained from all women before they completed the prequestionnaire and were sent a copy of the decision aid. Given that the pre and post questionnaires were administered over the telephone, the Ethics Committees gave approval for women to provide verbal informed consent. Verbal consent was obtained using a verbal consent script, which explained to participants that participation was voluntary and that they could withdraw at any time. The research team kept a verbal consent log of participants who verbally agreed to participate in the study.

\section{Consent for publication}

N/A

\section{Competing interests}

The authors declare that they have no competing interests.

\section{Publisher's Note}

Springer Nature remains neutral with regard to jurisdictional claims in published maps and institutional affiliations.

\section{Author details}

${ }^{1}$ Psychosocial Research Group, Lowy Research Centre, C25, Prince of Wales Clinical School, Faculty of Medicine, UNSW Sydney, Corner High and Botany St, Kensington, Sydney New South Wales 2033, Australia. ${ }^{2}$ Centre for Applied Nursing Research, School of Nursing and Midwifery, Western Sydney University, Ingham, Sydney, Australia. ${ }^{3}$ South Western Sydney Local Health District, Institute for Applied Medical Research, Sydney, Australia. ${ }^{4}$ Department of Obstetrics and Gynaecology, Royal Women's Hospital, University of Melbourne, Parkville, Australia. ${ }^{5}$ School of Women's and Children's Health, UNSW Sydney, Sydney, Australia. ${ }^{6}$ Department of Maternal-Fetal Medicine, Royal Hospital for Women, Sydney, Australia. ${ }^{7}$ Murdoch Children's Research Institute, Royal Children's Hospital, Parkville, Victoria, Australia. ${ }^{8}$ Department of Paediatrics, University of Melbourne, Parkville, Australia. ${ }^{9}$ Sydney School of Public Health, The University of Sydney, Sydney, Australia. ${ }^{10}$ School of Psychiatry, Faculty of Medicine, UNSW Sydney, Sydney, Australia. ${ }^{11}$ Sydney Medical School, The University of Sydney, Sydney, Australia. ${ }^{12}$ Women's Services, Liverpool Hospital, Sydney, Australia. ${ }^{13}$ Western Sydney University, Parramatta, Sydney, Australia.

Received: 20 March 2018 Accepted: 4 December 2018

Published online: 17 December 2018

\section{References}

1. Benn P, Borrell A, Jea C. Aneuploidy screening: a position statement from a committee on behalf of the Board of the International Society for Prenatal Diagnosis. Prenat Diagn 2011. 2011;31:519-22.

2. Bouman K, Bakker MK, Birnie E, ter Beek L, Bilardo CM, van Langen IM, de Walle HEK. The impact of national prenatal screening on the time of diagnosis and outcome of pregnancies affected with common trisomies, a cohort study in the northern Netherlands. BMC Pregnancy and Childbirth. 2017;17(1):4

3. Ward P, Soothill P. Fetal anomaly ultrasound scanning: the development of a national programme for England. The Obstetrician \& Gynaecologist. 2011;13(4):211-7.

4. EUROCAT (2010), EUROCAT Special Report: Prenatal Screening Policies in Europe 2010, EUROCAT Central Registry, University of Ulster. http://www. eurocat-network.eu/content/Special-Report-Prenatal-Screening-Policies.pdf. Accessed 11 Dec 2018 
5. St-Jacques S, Grenier S, Charland M, Forest J-C, Rousseau F, Légaré F. Decisional needs assessment regarding Down syndrome prenatal testing: a systematic review of the perceptions of women, their partners and health professionals. Prenat Diagn. 2008;28(13):1183-203.

6. Lou S, Mikkelsen L, Hvidman L, Petersen OB, Nielsen CP. Does screening for Down's syndrome cause anxiety in pregnant women? A systematic review. Acta Obstet Gynecol Scand. 2015:94.

7. Lo YMD, Corbetta N, Chamberlain PF, Rai V, Sargent IL, Redman CWG, Wainscoat JS. Presence of fetal DNA in maternal plasma and serum. Lancet. 1997;350(9076):485-7.

8. McLennan A, Palma-Dias R, da Silva CF, Meagher S, Nisbet DL, Scott F. Noninvasive prenatal testing in routine clinical practice - an audit of NIPT and combined first-trimester screening in an unselected Australian population. Aust N Z J Obstet Gynaecol. 2016;56(1):22-8.

9. Nicolaides $\mathrm{KH}$. Screening for fetal aneuploidies at 11 to 13 weeks. Prenat Diagn. 2011;31(1):7-15.

10. Gil MM, Akolekar R, Quezada MS, Bregant B, Nicolaides KH. Analysis of cellfree DNA in maternal blood in screening for aneuploidies: meta-analysis. Fetal Diagn Ther. 2014;35(3):156-73.

11. Taylor-Phillips S, Freeman K, Geppert J, Agbebiyi A, Uthman OA, Madan J, Clarke A, Quenby S, Clarke A. Accuracy of non-invasive prenatal testing using cell-free DNA for detection of Down, Edwards and Patau syndromes: a systematic review and meta-analysis. Brit Med J Open. 2016;6 http:// bmjopen.bmj.com/content/6/1/e010002.

12. Lewis $C$, Hill M, Chitty LS. Women's experiences and preferences for service delivery of non-invasive prenatal testing for aneuploidy in a public Health setting: a mixed methods study. PLoS One. 2016;11(4):e0153147.

13. Hill M, Fisher J, Chitty LS, Morris S. Women/'s and health professionals/' preferences for prenatal tests for Down syndrome: a discrete choice experiment to contrast noninvasive prenatal diagnosis with current invasive tests. Genet Med. 2012;14(11):905-13.

14. Allyse M, Minear M, Berson E, Sridhar S, Rote M, Hung A, Chandrasekharan S. Non-invasive prenatal testing: a review of international implementation and challenges. Int J Womens Health. 2015;7:113-26. Published online 2015 Jan 2016. https://doi.org/10.2147/IJWH.S67124.

15. Oepkes D, Page-Christiaens GC, Bax CJ, Bekker MN, Bilardo CM, Boon EMJ, Schuring-Blom GH, Coumans ABC, Faas BH, Galjaard R-JH, et al. Trial by Dutch laboratories for evaluation of non-invasive prenatal testing. Part I_clinical impact. Prenatal Diagnosis. 2016;36(12):1083-90.

16. Johansen P, Richter SR, Balslev-Harder M, Miltoft CB, Tabor A, Duno M, Kjaergaard S. Open source non-invasive prenatal testing platform and its performance in a public health laboratory. Prenat Diagn. 2016;36(6):530-6.

17. Chitty LS, Wright D, Hill M, Verhoef TI, Daley R, Lewis C, Mason S, McKay F, Jenkins L, Howarth A, et al. Uptake, outcomes, and costs of implementing non-invasive prenatal testing for Down's syndrome into NHS maternity care: prospective cohort study in eight diverse maternity units. Brit Med J. 2016;354.

18. Woolcock J, Grivell R. Noninvasive prenatal testing. Aust Fam Physician. 2014:43:432-4

19. HGSA/RANZCOG Joint Committee on Prenatal Screening and Diagnosis: Prenatal screening and diagnosis of chromosomal genetic conditions in the fetus in pregnancy. In.: The Royal Australian and New Zealand College of Obstetricians and Gynaecologists \& Womens Health Committee; 2016.

20. Dondorp W, de Wert G, Bombard Y, Bianchi DW, Bergmann C, Borry P, Chitty LS, Fellmann F, Forzano F, Hall A, et al. Non-invasive prenatal testing for aneuploidy and beyond: challenges of responsible innovation in prenatal screening. Eur J Hum Genet. 2015;23(11):1438-50.

21. de Jong A, Dondorp WJ, de Die-Smulders CEM, Frints SGM, de Wert GMWR. Non-invasive prenatal testing: ethical issues explored. Eur J Hum Genet. 2009;18(3):272-7.

22. van den Berg M, Timmermans DRM, ten Kate LP, van Vugt JMG, van der Wal G. Informed decision making in the context of prenatal screening. Patient Educ Couns. 2006;63(1-2):110-7.

23. Stacey $D$, Légaré $F$, Lewis K, Barry MJ, Bennett CL, Eden KB, Holmes-Rovner M, Llewellyn-Thomas $H$, Lyddiatt A, Thomson $R$, et al. Decision aids for people facing health treatment or screening decisions. Cochrane Database Syst Rev. 2017:4:CD001431. https://doi.org/10.1002/14651858.CD001431.pub5.

24. Vlemmix F, Warendorf JK, Rosman AN, Kok M, Mol BWJ, Morris JM, Nassar N Decision aids to improve informed decision-making in pregnancy care: a systematic review. BJOG Int J Obstet Gynaecol. 2013;120(3):257-66.
25. Leiva Portocarrero ME, Garvelink MM, Becerra Perez MM, Giguère A, Robitaille H, Wilson BJ, Rousseau F, Légaré F. Decision aids that support decisions about prenatal testing for Down syndrome: an environmental scan. BMC Medical Informatics and Decision Making. 2015;15(1):76.

26. Beulen $L$, van den Berg M, Faas BHW, Feenstra I, Hageman M, van Vugt JMG, Bekker MN. The effect of a decision aid on informed decision-making in the era of non-invasive prenatal testing: a randomised controlled trial. Eur J Hum Genet. 2016;24(10):1409-16.

27. Portocarrero MEL, Giguère AMC, Lépine J, Garvelink MM, Robitaille H, Delanoë A, Lévesque I, Wilson BJ, Rousseau F, Légaré F. Use of a patient decision aid for prenatal screening for Down syndrome: what do pregnant women say? BMC Pregnancy and Childbirth. 2017;17(1):90.

28. McCray AT. Promoting Health literacy. J Am Med Inform Assoc. 2005;12(2): 152-63.

29. Nutbeam D. Defining and measuring health literacy: what can we learn from literacy studies? Int J Public Health. 2009;54(5):303-5.

30. ABS: Adult Literacy and Life Skills Survey, Summary Results. Canberra: Australian Bureau of Statistics: Australian Government Publishing Service. Cat No. 4228.0; 2006.

31. Nagle C, Gunn J, Bell R, Lewis S, Meiser B, Metcalfe S, Ukoumunne OC, Halliday J. Use of a decision aid for prenatal testing of fetal abnormalities to improve women's informed decision making: a cluster randomised controlled trial [ISRCTN22532458]. BJOG: An International Journal of Obstetrics \& Gynaecology. 2008;115(3):339-47.

32. Smith $S$, Sousa M, Essink-Bot ML, Halliday J, Peate M, Fransen $M$. Socioeconomic differences in informed decisions about Down syndrome screening: a systematic review and research agenda. J Health Commun. 2016:21(8):868-907.

33. Nagle C, Lewis S, Meiser B, Metcalfe S, Carlin JB, Bell R. Evaluation of a decision aid for prenatal testing of fetal abnormalities: a cluster randomised trial [ISRCTN22532458]. BMC Public Health. 2006;6:96

34. Volk RJ, Llewellyn-Thomas H, Stacey D, Elwyn G. Ten years of the international patient decision aid standards collaboration: evolution of the core dimensions for assessing the quality of patient decision aids. BMC Medical Informatics and Decision Making. 2013;13(2):S1.

35. NSW Health's Centre for Genetics Education: Prenatal testing - Special tests for your baby during pregnancy. Edited by www.genetics.edu.au. 2013.

36. Willis AM, Smith SK, Meiser B, Muller C, Lewis S, Halliday J. How do prospective parents prefer to receive information about prenatal screening and diagnostic testing? Prenat Diagn. 2015;35(1):100-2.

37. Doak CCD, L. G, Root JH. Teaching patients with low literacy skills. 2nd ed. Philadelphia: J.B. Lippincott; 1996.

38. Clerehan R, Buchbinder R, Moodie J. A linguistic framework for assessing the quality of written patient information: its use in assessing methotrexate information for rheumatoid arthritis. Health Educ Res. 2005;20(3):334-44.

39. McCaffery K, Holmes-Rovner M, Smith S, Rovner D, Nutbeam D, Clayman M, Kelly-Blake K, Wolf M, Sheridan S. Addressing health literacy in patient decision aids. BMC Med Inform Decis Mak. 2013;13(Suppl 2):S10.

40. Houts PS, Doak CC, Doak LG, Loscalzo MJ. The role of pictures in improving health communication: a review of research on attention, comprehension, recall, and adherence. Patient Educ Couns. 2006;61(2):173-90.

41. South Western Sydney Local Health District. Health Profile of Local Communities. In: 3. Sydney: Local Health District. Accessed 4 July 2018, https://www.swslhd.health.nsw.gov.au/planning/content/pdf/ SWSLHD\%20Community\%20Profile\%20Summary\%20070814.pdf; 2014.

42. The Royal Australian and New Zealand College of Obstetricians and Gynaecologists: Shared maternity care obstetric patients In., edn. Melbourne, Australia: Training, Accreditation and Recertification (TAR) Subcommittee of the Conjoint Committee for the Diploma of Obstetrics and Gynaecology (CCDOG) and approved by the RANZCOG Board and Council.; 2016.

43. Health NSW. Prenatal testing/screening for Down syndrome and other chromosomal abnormalities. Sydney, NSW: Australia: NSW Health, Ministry of Health; 2013.

44. Wakefield CE, Meiser B, Homewood J, Peate M, Kirk J, Warner B, Lobb E, Gaff C, Tucker K. Development and pilot testing of two decision aids for individuals considering genetic testing for Cancer risk. J Genet Couns. 2007;16(3):325-39.

45. Wakefield CE, Watts KJ, Meiser B, Sansom-Daly U, Barratt A, Mann GJ, Lobb EA, Gaff CL, Howard K, Patel MI. Development and pilot testing of an online 
screening decision aid for men with a family history of prostate cancer. Patient Educ Couns. 2011;83(1):64-72.

46. Hyett J, Mogra R, Sonek J. First trimester ultrasound assessment for fetal aneuploidy. Clin Obstet Gynecol. 2014;57(1):142-58.

47. Smith SK, Dixon A, Trevena L, Nutbeam D, McCaffery KJ. Exploring patient involvement in healthcare decision making across different education and functional health literacy groups. Soc Sci Med. 2009;69(12):1805-12.

48. Reyna VF. A theory of medical decision making and health: fuzzy trace theory. Medical Decis Making. 2008;28:850-65.

49. Setton R, Wilhelms E, Weldon B, Chick C, Reyna V. An overview of judgment and decision making research through the Lens of fuzzy trace theory. Xin li ke xue jin zhan. 2014;22(12):1837-54.

50. Schoonen H, van Agt HME, Essink-Bot M-L, Wildschut HI, Steegers EAP, de Koning HJ. Informed decision-making in prenatal screening for Down's syndrome: what knowledge is relevant? Patient Educ Couns. 2011;84(2):265-70

51. Smith SK, Trevena L, Simpson JM, Barratt A, Nutbeam D, McCaffery KJ. A decision aid to support informed choices about bowel cancer screening among adults with low education: randomised controlled trial. Brit Med J. 2010;341:C5370

52. Michie S, Dormandy E, Marteau TM. Increasing screening uptake amongst those intending to be screened: the use of action plans. Patient Educ Couns. 2004:55(2):218-22.

53. Lee PY, Khoo EM, Low WY, Lee YK, Abdullah KL, Azmi SA, Ng CJ. Mismatch between health-care professionals' and patients' views on a diabetes patient decision aid: a qualitative study. Health Expect. 2016;19(2):427-36.

54. Legare F, Stacey D, Briere N, Fraser K, Desroches S, Dumont S, Sales A, Puma C, Aube D. Healthcare providers' intentions to engage in an interprofessional approach to shared decision-making in home care programs: a mixed methods study. J Interprof Care. 2013;27.

55. Elwyn G, Laitner S, Coulter A, Walker E, Watson P, Thomson R. Implementing shared decision making in the NHS. Brit Med J. 2010;341.

56. Harrison JD, Masya L, Butow P, Solomon M, Young J, Salkeld G, Whelan T. Implementing patient decision support tools: moving beyond academia? Patient Educ Couns. 2009;76(1):120-5.

57. Stevens G, Thompson R, Watson B, Miller YD. Patient decision aids in routine maternity care: benefits, barriers, and new opportunities. Women and Birth. 2015;29(1):30-4.

58. Lépine J, Leiva Portocarrero ME, Delanoë A, Robitaille H, Lévesque I, Rousseau F, Wilson BJ, Giguère AMC, Légaré F. What factors influence health professionals to use decision aids for Down syndrome prenatal screening? BMC Pregnancy and Childbirth. 2016;16(1):262.

59. Garvelink MM, ter Kuile MM, Stiggelbout AM, de Vries M. Values clarification in a decision aid about fertility preservation: does it add to information provision? BMC Medical Informatics and Decision Making. 2014;14(1):68.

60. Peate M, Watts K, Wakefield CE. The 'value' of values clarification in cancerrelated decision aids. Patient Educ Couns. 2013;90:281-3.

61. Carroll FE, Al-Janabi H, Flynn T, Montgomery AA. Women and their partners' preferences for Down's syndrome screening tests: a discrete choice experiment. Prenat Diagn. 2013;33(5):449-56.

62. Carroll FE, Owen-Smith A, Shaw A, Montgomery AA. A qualitative investigation of the decision-making process of couples considering prenatal screening for Down syndrome. Prenat Diagn. 2012;32(1):57-63.

63. Joseph G, Kaplan CP, Pasick RJ. Recruiting Low-income healthy women to research: an exploratory study. Ethnicity \& health. 2007;12(5):497-519.

64. Bonevski B, Randell M, Paul C, Chapman K, Twyman L, Bryant J, Brozek I, Hughes $C$. Reaching the hard-to-reach: a systematic review of strategies for improving health and medical research with socially disadvantaged groups. BMC Med Res Methodol. 2014;14(1):42.

65. Cottrell E, Roddy E, Rathod T, Thomas E, Porcheret M, Foster NE. Maximising response from GPs to questionnaire surveys: do length or incentives make a difference? BMC Med Res Methodol. 2015;15:3.

66. Stetler CB, Damschroder LJ, Helfrich CD, Hagedorn HJ. A guide for applying a revised version of the PARIHS framework for implementation. Implement Sci. 2011;6:99.

67. Evans WD. How social marketing works in health care. Brit Med J. 2006; 332(7551):1207-10

\section{Ready to submit your research? Choose BMC and benefit from:}

- fast, convenient online submission

- thorough peer review by experienced researchers in your field

- rapid publication on acceptance

- support for research data, including large and complex data types

- gold Open Access which fosters wider collaboration and increased citations

- maximum visibility for your research: over $100 \mathrm{M}$ website views per year

At BMC, research is always in progress.

Learn more biomedcentral.com/submissions 